\title{
Our Strength Is In Our Diversity: Fact Or Fancy?
}

Charles S. Domina, Nova Southeastern University, USA

\begin{abstract}
The following article, under the above title, addresses the concept and ideology surrounding diversity, its inexorable relation to affirmative action, and other related ideological and political belief systems. The efficacy of diversity, as currently defined, is examined, as well as its application in the world of education and business. The uniqueness, or lack thereof, of diversity in modern day America is explored as is the overwhelming importance to which it has been elevated. The intent, herein, is to raise and discuss the issues(s) as to whether or not the popular and much used phrase, "Our strength is our diversity," is a statement of factual substance or is, rather, a mantra to create a fanciful and destructive illusion in order to advance a political agenda.
\end{abstract}

\section{INTRODUCTION}

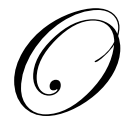

ur strength is in our Diversity?" It is posed as a question rather than as a statement of fact as is the conventional wisdom of the day, so much so that it has taken on a dimension and inertia of its own. What is diversity? Is it new? If not, why is it being recognized to such an extent now, and, in many quarters, why has it become no less than a political movement? Does diversity stand alone or is it inexorably linked with and the progeny or, very possibly, the doppelganger of the growingly disfavored affirmative action, but, wrapped in a more palatable and "progressive" package? What is the effect of diversity, in its current application, socially and more importantly, for our present purposes in business? What is the effect of diversity in our education system, particularly at the college and post-graduate level which is the training ground for those who will be expected to compete domestically and in the global market place? What are the implications for management? But first, a little background, by way of example, on what might be designated as a reality check on the unintended consequences of applied diversity.

The dust had barely settled, and the cleanup of the World Trade Center, as of January 2002, was nowhere near completion. In some circles, hopes already had been dashed for a renewed spirit of American solidarity and for a rejection of the toxic ideology of those who foment conflict in the name of diversity. It was not long before the attitudes and conduct which had been exhibited before the events of 9/11 "reared their ugly heads." The term dead white men resurfaced in newspaper reports of a New York politician who, in the best or, possibly, worst tradition of neo-diversity, referred to the father of our country and our first president, George Washington, using that term. This was in conjunction with an announcement that he was going to remove Washington's portrait from his office, in Brooklyn Burrough Hall, for reasons that were never fully clear save for the fact that he mentioned something about having his office reflect the area's ethnic mix.

Not to be outdone, a newly elected New York City Council member, a former Black Panther, demanded that the portrait of Thomas Jefferson should be removed from City Hall. Among other divisive and hateful rhetoric, he labeled Jefferson a pedophile in reference to the unsubstantiated allegation that Jefferson had an affair with Sally Hemmings, a young slave girl. He stated that because $65 \%$ of New Yorkers are "people of color," a designation which is so fluid and overused as to have lost any objective meaning, that a majority of the pictures in City Hall should be those of prominent African-Americans. This was, of course, a validation, despite denials, that the application of racial and ethnic quotas is alive and well and continued to be demanded even while the ruins of the World Trade Center were smoldering and rescue workers of all races and ethnicities were attempting to retrieve the bodies of murdered victims of all races and ethnicities. 
Perhaps the most disturbing incident, post $9 / 11$ and that best illustrates the issue, was the proposed monument of the three firemen raising the American flag in a pose reminiscent of Iwo Jima. It was disturbing not only because it raised conflict among Americans at a time when solidarity should have been the order of the day, but also, because it took place, once again, in the city that was the site of the attack and that should have been the last place where racial and ethnic differences were emphasized or amplified. To have done so was to have done a great disservice to the country, in a time of crisis, in order to advance a political agenda. Yet, not to be thwarted in their zeal, those who believe that diversity, or at least their version of it, trumps all, proceeded to direct that the faces of the firemen show an ethnic mix as opposed to being the Caucasians who they actually were. Arguments that this was a depiction of a historical event and demanded accuracy, not political correctness, fell on deaf ears. This is the way of those who are blinded by extremist diversity. There were the usual denials by those who tried to rationalize or to delude themselves into believing that their own agenda was not the motivating force. These, however, are the people who harm society because they will not see, nor admit if they do see, the real reasons for their actions-the misguided social philosophies that they advance and the things with which they burden those who do not subscribe to their vision of the world.

Amidst it all, a new phrase was added to the political lexicon by the proponents of diversity and those who wanted the racially mixed statue. They asserted that it was necessary to change the race of the various white firefighters in order to maintain "cultural decency." However, it was not decency, cultural or otherwise, that was in operation. It was history revisionism. The monument controversy was instructional and had the positive effect of casting a bright light on the diversity issue for all to see. The bronze statue was to be a tangible artifact and a symbol possessing materiality rather than an obscure belief. These attributes made it possible to see, clearly, how far some would go in advancing the politics and the agenda of diversity. Unfortunately, because of the controversy stirred up by the diversity activists, the project was abandoned and all that we were left with was a stamp.

Affirmative action, as a belief system, intends the same outcome using, basically, the same methodology. Both look at people, not as individuals but rather as members of one group or the other, exclusively those that have a minority or government protected designation. In a sense, diversity issued from affirmative action as being a more equitable solution to "leveling the playing field." However, those who advance the doctrine of diversity have taken the worst from affirmative action: racial and ethnic quotas. Having a "Cabinet that looks like America" was a popular slogan of the Clinton Administration. With that, racial and ethnic preferences were entrenched in the American psyche and became an end in and of themselves. History, on the other hand, has those who have had a contrary viewpoint regarding the advancement of protected groups based on racial and ethnic considerations irrespective of the label one wishes to attach to the idea. Philip K. Humphrey (1994), in his book The Death of Common Sense, quotes the late Hubert Humphrey, in referencing a portion of the Civil Rights Act of 1964, as saying:

If anyone can find in Title VII . . any language which provides that an employer will have to hire on the basis of percentage or quota related to color race, religion or national origin, I will start eating the pages one after another, because it is not there. (p. 22)

Mr. Humphrey (as cited in Abram, 1986) sounded a further note and asked a question which turned out to be in the nature of a prediction when he said:

Our standard of judgment in the last analysis is not some group's power . . but an equal opportunity for persons. Do you want a society that is nothing but an endless power struggle among organized groups? Do you want a society where there is no place for the independent individual? I don't. (p. 1322)

It is a point of interest that the principles of affirmative action and diversity, before they became known as such, were both commented on over 100 years ago by Frederick Douglas. Major Martin Delaney, a Black friend of Mr. Douglas, had argued that Black people deserved government appointments based on their numbers, in fact, a quota system. Douglas (as cited in Abram, 1986), in rebuke of that position and to illustrate its fallacious reasoning, wrote: 
The mallatoes, on a solid census basis ought to have so many offices, the blacks so many, the Germans so many, the Irish so many and other classes should have offices according to their respective numbers .... Upon your statistical principle, the colored people of the United States ought, therefore, not only to hold one-eighth all of the offices in the country, but, they should own one-eighth of all the property and pay one-eighth of all the taxes of the country. They should constitute one-eighth of the poets, statesmen, scholars, authors and philosophers of the country. (p. 1315)

Those who would give this commentary short shrift or discount it as hyperbole, notwithstanding the fact that the words are those of one of history's great names in civil rights and are dead on as to what is happening today, must still reconcile those words with the present trends of affirmative action/diversity, which, at the present time, have increased in scope and have been applied to an ever-growing number of members of government protected groups. In fact, the argument of those who advocate wide ranging preferences replete with self-serving statistics that some group or the other comprises a certain percentage of the population but only makes up an unrepresentatively small percentage of CEOs or firefighters or police officers or B-52 pilots or, you name it, the choices are many, is all too familiar and advocates an agenda of a quota system while simultaneously denying same. The implicit demand is that there must be representation, in each classification, proportional to the percentage of members of the protected group in the general population. All of the rhetoric and demands of the advocates point to this conclusion in spite of their protestations and denials or convoluted semantics where discrimination of the so-called "reverse" kind becomes a form of inclusion rather than exclusion and where quotas, in order to defuse the arguments against them, are not eliminated but, rather, are conveniently called goals. The "level playing field" has disappeared into a downward spiraling vortex created by those who demand equality in numbers based on racial, ethnic, and sexual proportionality as opposed to judging individuals as individuals.

What the social engineers fail to perceive is that societies that depart from color blind neutral decision making, do so at their own peril. The history of societies that have adopted this approach in order to reach substantive social goals more quickly, has been a history not of liberation, but, of crippling oppression. (Abram, 1986, p. 1315)

Those who held the belief that affirmative action was to be the never ending wave of the future, only to watch it gain growing disfavor in the public arena, decided not to wait for the outcome of the war between those who are for versus those who are against. They, instead, decided to put Plan B into action, without further delay: enter, diversity. We are told that diversity is good; in fact, it is indispensable. Schools, in particular, institutions of higher learning, cannot function without it. America cannot compete in a global economy without business being diverse. We must promote diversity in order for our domestic economy to survive. In fact, the corner grocery store cannot be successful unless it is run by or employs people of the same ethnic or racial group that lives in the neighborhood. A suggestion which would seem to indicate, if it were true, that the neighborhood is occupied by bigots who will only do business with you if you are "one of them." It has commanded sensitivity training and diversity management programs be implemented. It is almost enough to make one nostalgic for good old fashioned affirmative action.

Is diversity a gift to America or is it America's Trojan horse? That depends on how it is currently approached. As an educated citizenry is one of the pillars upon which business and the economy is based, a review of diversity in education warrants a brief review. Two particular situations come to mind.

The first situation has to do with the spectacle, televised a few years ago, of an Asian mother sitting in front of a government committee testifying that her daughter was denied admission to a magnet school even though she had scored in the highest percentile with regard to admission requirements. Based on her academic record, there absolutely was no reason for the denial. Why then was admission refused? The answer was the essence of simplicity itself, at least in the world of those who worship at the altar of diversity. It seems that the school already had filled its quota of Asians, and there was no more "room at the inn," so to speak. Something unusual and unforeseen had occurred. There was a designated minority, the members of which excelled in academic studies. In fact, they more than excelled. They "beat the pants off" all other groups, including Whites, in such areas as science and math. This, of course, threw the grand plan of diversity totally out of balance. 
So, what should be done? Without missing a beat, those of the diversity culture decided that the only way to treat individuals of achievement, no matter who they may be, was to discriminate against them. But, wait! Is this real discrimination? After all, Asians are a government protected minority group. So, if the government decides to discriminate against a member of one minority group in favor of a member of another minority group rather than discriminating against a member of a minority group in favor of an individual who is not a member of a minority group, is this real discrimination? Or could it be that when a minority group exhibits achievement and they are discriminated against, it is not the bad kind of discrimination but rather the not-so-bad kind of discrimination: reverse discrimination? It all becomes very confusing. What is not confusing, however, is the message that such actions transmit. They say, in unequivocal terms, that if the government stands, always, at the ready to give a group favored treatment, then the individuals of that group are considered underachievers, by nature, and must receive that advantage or fail. Should they dare have the audacity to achieve, then they can go to the back of the line and join those who do not enjoy the privileged treatment accorded to those who are members of protected groups.

A second set of examples are situations of significantly more gravity as they involve the compromising of standards in professional schools. More precisely, the examples involve admissions policies of various law schools located in the state of California which, at the time, put them on a collision course with Prop 209.

"The News Hour" with Jim Lehrer, broadcast on PBS a few years ago, presented a piece entitled "Building Diversity." It dealt with minority admissions to three California law schools: Stanford, Boalt Hall-University of California at Berkley, and Hastings Law School located in San Francisco.

The Dean of Boalt Hall, Herma Hill Kay, in order to "build diversity," appointed Robert Cole as Chairman of the Admissions Task Force. On being interviewed, Mr. Cole said some interesting things: To quote one of them, "You cannot have a first-class law school . . . without racial and ethnic Diversity" (Cole, 1999, para. 6). This is a curious position for an educator to take in that traditionally, whether any school, law or otherwise, was or was not first class depended on such things as its academic standards (including admissions requirements), the quality of its faculty, and the demands placed on the student body to take on a heavy academic load and to excel. The criteria, at least up until now, have never been based on the skin color, ethnicity, national origin, or sex of the members of said student body. Chairman Cole, in response to further questioning, then stated an additional reason for diversity building: "It improves the quality of the education, and because people are going to go out and be in positions of leadership, they have to be educated through a more diverse student body" (Cole, 1999, para. 6).

This statement is puzzling when listened to, but becomes downright bewildering when put it down on paper and read it. Mr. Cole never was asked to explain the dynamics of the logic that would lead one to conclude that education is improved simply by the fact that the students in a given class exhibit different varieties of skin color, bone structure, and hair texture, which is how diversity is presently measured and judged. Mr. Cole continued the interview, but continued to answer by reciting platitudes, never going into any meaningful explanation that would reveal the logic of his assertions. Apparently, Boalt Hall, by and through the leadership of Chairman Cole, laid down a policy of emphasizing their unique brand of achievement, measured in part by essays submitted by prospective candidates, apparently setting forth such things as background and life experience, although it was not clearly set out how these essays were, in fact, used or how much weight was given to them.

What was clearly set out was the fact that less emphasis would be placed on undergraduate grades and the Law School Admissions Test (LSAT). The reason for this, Chairman Cole explained, was because such tests create a barrier to some minorities. This may be a valid explanation to Chairman Cole, but is testing not all about creating barriers to those who have not met the required academic standards? Is that not why the policies of open admissions and social promotions, implemented over the last three decades, have been an abysmal failure? It is disturbing to see that anyone in the position of Chairman Cole could suggest that a policy of encouraging application to law school by minorities, accepting them by discarding the demand for high academic qualifications, and replacing such qualifications with some amorphous standard such as an essay, which has the potential to be subjectively graded to assure a minimum quota of minority admissions, will, in any way, enhance the academic standing of Boalt Hall. How can such practices improve the academic quality of the curriculum, the legal education of the student body in general, or the ability of those minorities accepted into the system to complete a course of studies and graduate armed with the knowledge and skills necessary to compete in a profession where excellence is demanded and competition is everything? 
Administrator Mary Kay Kane explained that Hastings Law School had something called a Legal Opportunity Education program (LEOP), which is sort of an academic assistance program that the law school put into effect to support a 30-year old policy of reserving $20 \%$ of places in each class for those whose social experience, education, economic status, or disability puts them at a disadvantage. This, in a very real sense, sounds like open admissions and remedial studies, revisited. The contention is that the policy is not race-based. Technically that may be true, but the categories are such that it is almost certain most of the candidates who fall into these categories will be a minority; a sad commentary as to the general educational system beset by flawed philosophies which, looking at Hastings admissions policy, are being perpetuated in the nation's institutions of higher learning. That, unfortunately, is the result when political agendas trump education.

Last, the focus turns to Stanford law School. Dean Paul Brest (1999) unabashedly declared that, yes, race is one of the considerations in admission to Stanford. Yet, Dean Brest can be unabashed about such things as Stanford is a private institution and not covered by Prop 209, although there might be a problem if it is a recipient of any government funding. During the interview, Dean Brest, when asked about the admission of Blacks and Chicanos, stated the following: "We would think that we could not give the student body as a whole the kind of professional education we do if we didn't have members of those minority groups."

He continued, in his explanation, by saying that applicants are judged not only on grades but on life experience. Life history is used to overcome test scores. Comparing the quotes of Chairman Cole of Boalt Hall and Dean Brest of Stanford, one might be led to believe that both attended the same diversity workshop.

What is abundantly clear is that what is passing for a logical and acceptable explanation in the previous examples, as to the application of diversity, is nothing more than a lot of high minded, disingenuous drivel. The lowering of academic standards is destructive, not constructive, to a learning environment. Diversity reigns supreme, at any cost. Children are being undereducated, particularly minorities, in grammar school. Then they are passed on to junior high and senior high without the necessary skills. It is then demanded that unprepared individuals be allowed access to college, and to accomplish this, the Scholastic Aptitude Test (SAT) is being attacked as unfair and ethnically and culturally biased. There is a movement to discard it or diminish its application, much in the same way the LSAT exam is being disregarded by the aforementioned law schools. It is most unfortunate that those who call themselves educators are putting the shallowness and artificiality of diversity ahead of sound academic standards and have decided that it is more propitious, for the advancement of their own social beliefs and agenda, to lower the bar of achievement and excellence so as to significantly diminish American education, which is having and will continue to have serious rippling effects on all aspects of this country in the social and business sectors. Those who would put diversity, or their concept of it, above the pursuit and acquisition of knowledge by individuals are living in an ideological dream world and are perpetrating a fraud on their institutions; on the student population, in general; on the minority student population, in particular; and on the country. Nothing good as to the advancement of education came from busing, social promotions, or the open admissions policies of old that were instituted in the name of affirmative action. These were nothing more than ineffective political solutions applied in order to paper over a systemic problem of bad education. Likewise, nothing good will come from the scholastically counterfeit admissions policies carried on under the banner of diversity by Boalt Hall, Stanford, Hastings, or any other school that opts to travel down this dead end road.

Diversity, in a real sense, has imposed itself on business rather than being voluntarily adopted by it in spite of the fact that companies tend to congratulate themselves for their diversity policies and programs. In fact, many of these companies have become virtual monuments to diversity. Upon entering their premises, one is overwhelmed by a cornucopia of posters, slogans, employee works of art, racks of flyers, and notices from a dazzling variety of clubs, all dedicated to fostering diversity and all that goes with it, as presently defined.

Even the very theory behind the current push for diversity is flawed. In fact, diversity has always been in America. It is the natural order of things, yet it is currently treated as if it is a new phenomenon. Until fairly recently, the majority of the citizenry of this country, save for the Blacks whose ancestry is African, originated in the countries of Western Europe and the Mediterranean. Yet that does not mean they were and are not diverse. An Italian is not a Swede, is not an Irishman, is not a German, is not a Spaniard, is not a Greek, and so forth. All are of unique cultures with different languages, societal mores, food, art, music, and all of those things that make each 
country and its people distinct. Yet, in present day America, they are considered homogeneous and are referred to as Europeans or Anglos or non-this that or the other thing. People have, however, taken great notice of the new immigrant who may come from such places as Asia or the Asian sub-continent or the Middle East. These are the people who are considered to be the ones who represent diversity - but why? The answer is simple. To one extent or the other, they are people of color, or at least non-Caucasian. Physical characteristics or ethnicity have become the measure of diversity, and this is how it is applied.

It is suggested that there is some connection between the capacity of a person to make a contribution to some endeavor and that person's race or ethnicity. The statements of the administrators of the California law schools together with the fact that diversity was measured by ethnic and racial mix, not by intellectual or cultural contribution, illustrates this to be a fact. Another example is the promotion, by the corporate world, that it is necessary to have individuals of diverse races and ethnicities to transact business at the local, national, and international level. Thomas Sowell (2003), a renowned, Black, conservative economist, asks the question,

How do companies in Japan manage to sell everything from cars to cameras, in countries around the world, without having that mystic 'diversity'? How does a country with such a racially homogenous population even manage to educate its young people if 'diversity' is such an essential factor in education?

The reality is that people are not imbued with cultural traits or special knowledge by virtue of genetics. If, for instance, an American company were doing business in Japan, it would make more sense to hire a Caucasian of Irish extraction who held graduate degrees in Japanese language and culture than it would to hire someone of Japanese extraction who was raised in South Dakota. If the Spanish language is a necessary requisite for a business, it should be enough to hire an individual who is fluent in Spanish, not that a Hispanic must be hired. Likewise, even on a local level, one would hope that people would go to the best store where they could buy the best product and get the best service rather than patronizing a business simply because it is owned or run by someone of their own race or ethnicity. The latter is an attitude that business should not be encouraging, but that is exactly what diversity programs do. There is a running joke about The New York Times editorial department to the effect that it is very diverse. They employ liberal Whites, liberal Blacks, liberal Asians, liberal Hispanics, liberal men, and liberal women. They are very diverse, at least according to the current definition.

That many proponents argue in favor of diversity by couching it in terms of anti-discrimination policy by limiting it to a Black/White issue, because that makes it easier to argue the point, or by suggesting that diversity has more to do, predominately, with culture and outlook which, at the best, is disingenuous. The fact is that in the final analysis, whether or not a company is diverse has mainly to do with its racial and ethnic mix of its employee group as it relates to the demographics of the local population.

Why do companies embrace diversity? It is not because they have become enlightened over the past 20 years. It is more because a "loaded gun," with the Equal Employment Opportunity Commission's (EEOC) finger on the trigger is, still pointed at them in the form of the threat of affirmative action enforcement as well as private law suits for racial discrimination, both concepts working against business. As Thomas Sowell (2003) put it,

If a corporation does not have enough minority employees to satisfy government agencies, that can lead to racial discrimination lawsuits. But if they hire by quotas and quotas are outlawed, they can be sued by whites for racial discrimination. Keeping affirmative action legal solves the problem.

Diversity allows hiring by quotas, which protects against lawsuits by minorities, and affirmative action laws prevent lawsuits by Whites, which might result from hiring on the basis of racial and ethnic quotas. It just sort of all dovetails together. Corporate America has decided to go along to get along, as the saying goes.

But, has the practice and implementation of diversity been as benign and positive as we have been led to believe? Has it, rather than bringing people together, been divisive and harmful in its nature and result? Many times when discussing or reading about diversity, the term "melting pot" comes up. Advocates will suggest that diversity is synonymous with that principle. They would be wrong. That idea has long been used to identify the process of assimilation and the putting aside of differences in order to accomplish a common goal. Formerly, when people went 
to work, they went there for that purpose - to work and to accomplish common goals and not for the purpose of "celebrating" their diversity.

A true and meaningful application of diversity, that is, people coming from diverse backgrounds and utilizing their distinct talents to pursue a common goal, took place in the early 1900s in Monterey Bay, California at a place called Cannery Row. This landmark has become a world famous tourist attraction due in large part to the writings of John Steinbeck, but for the first half of the twentieth century it was the center of the sardine fishing industry in the United States. Those who built the fish packing factories quickly came to the realization that, although being innovators and high powered industrialists, they were unskilled in fishing for sardines. Enter a Sicilian immigrant by the name of Pietro Ferrante and others from the sizable Southern Italian community living in the Monterey area. They applied their skills and knowledge, honed in the old country as a result of generations of fishing, to lead the way in their new country. Innovations were introduced, such as the lampara (a small, fast fishing boat used for night fishing by lamplight) and the purse net to increase the volume of each individual haul. Ferrante and his fellow countrymen were not welcomed into the sardine industry because some government agency demanded it in order to establish demographic parody but, rather, because these individuals, as individuals and not as members of some government "protected group," had a meaningful and indispensable contribution to make to an American industry.

Paying homage to one's heritage was left to private moments with the family and the occasional ethnic festival. That philosophy worked pretty well to get this country where it is now, over the last 233 years.

Diversity programs cost money, time, and energy and would seem to be disruptive by emphasizing differences rather than similarities and in some instances advocating mores, which may be offensive to others, thereby creating friction rather than allaying it. Because of the overwhelming promotion of diversity in many companies coupled with the necessity to institute "diversity management" programs, the whole exercise takes on a cultist tone of corporate brainwashing, where many who are subjected to this system may do so out of financial necessity rather than desire. But, one must learn it, live it, and love it or suffer the stigma of being an outsider in the corporate culture; not a comfortable place to be.

What is even more insidious is the specter of a company taking what amounts to a political position on an issue. Such was the case in a situation that arose at Hewlett-Packard in Boise, Idaho. The story appeared in a news release on the NewsMax website on January 8, 2004. As it is short, the pertinent parts will be quoted here, in their entirety, for proper clarification.

Hewlett-Packard had the right to fire an employee who posted anti-sodomy Bible verses at his own cubicle to protest the company's "diversity" policy, the 9th U.S. Circuit Court of Appeal stated:

HP had fired Richard Peterson in Boise, Idaho, after he displayed biblical passages about making sodomy punishable by death.

Peterson said that the company discriminated against him and that other employees were allowed to display religious symbols and pro-diversity posters.

Peterson was fired because he violated the company's harassment policy by attempting to generate a hostile and intolerant work environment' and disobeyed manager's orders to remove the passages, Circuit Judge Stephen Reinhardt said. ("Bible passages," 2004)

Granted, Richard Peterson's actions were extreme, but it is likely that the result would have been the same had any fundamentalist biblical passages been displayed to counter the company's diversity policy. That is the problem with formalized diversity entering the workplace. Once one allows it, it opens the door. If one is selective, it no longer is diversity but, rather, the advancement of a political, social, or legal agenda being imposed on workers, a pattern of corporate conduct which has no place in the business arena, at least not in America.

In Orwell's dystopian world, Oceana, Newspeak serves the ideological goals of Insoc--English Socialism. It gradually replaces Oldspeak in defining politics and culture. Without the words necessary, complex thoughts simply 
cannot be expressed.

The evolution of PCspeak parallels that of Newspeak. Consider the evolution of public debate on affirmative action or, more broadly, "diversity."

First, there is the introduction of doublethink. Doublethink occurs when someone simultaneously accepts two contradictory beliefs as true. A common argument for affirmative action: It is wrong to judge people on the basis of skin color or gender; therefore, universities and employers should give preference to people based on skin color and gender.

Second, euphemistic “doublespeak” makes doublethink positions acceptable. The term 'affirmative action' strongly implies a positive and correct action. Third, language is controlled to define the ensuing debate. (McElroy, 2003, paras. 3-6)

The previous analysis echoes the discussion in Lewis Carroll's Through the Looking Glass, where Alice and Humpty Dumpty have the following exchange:

"When I use a word," Humpty said, in a rather scornful tone, "it means what I choose it to mean, neither more nor less."

"The question is, " said Alice, "whether you can make words mean so many different things."

“The question is, ” said Humpty Dumpty, “which is to be master, that's all.” (Carroll, 1960, p. 186)

The question still remains. Who is to be master? Will corporate America stand for clarity and excellence and fight to encourage that on the rest of society, most importantly, in the halls of learning? Will it champion the cause in a country that needs excellence to maintain its leadership in the world? Or, will it allow itself to become caught up in the tides and currents of social engineering and theories based on empty platitudes which never have carried those who rode them to any positive or worthwhile destination? Perhaps business should get out of the business of diversity and concentrate on the business of conducting business. If it does that and does it well, all the rest will follow.

\section{AUTHOR INFORMATION}

Charles Domina is presently and has been a member of the adjunct faculty at Nova Southeastern University since 1981. His degrees earned are an AB in Psychology (1965) and a JD (1968), both from the University of Miami. Charles Domina engaged in the private practice of law for 21 years and was an entrepreneur for 14 years, primarily as a founder, shareholder, officer, and director of four closely held corporations, two of which did business overseas, one doing business with German interests, and one doing business with interests in the U.K. Presently, in addition to teaching duties with Nova, Charles Domina is a founder of and principle in a non-profit corporation whose mission is to administer and obtain funds for surgical and medical teams who provide pro bono care to the children of the country of Haiti.

\section{REFERENCES}

1. Abram, M. B. (1986). Affirmative action: Fair shakers and social engineers. Harvard Law Review, 99, 1312-1326.

2. Bible passages a firing offense. (2004, January 7). Retrieved from http://archive.newsmax.com/archives/ic/2004/1/7/155553.shtml

3. Brest, P. (1999, January 18). Redefining diversity. Retrieved from PBS website: http://www.pbs.org/newshour/bb/education/jan-june99/diversity_1-18.html

4. $\quad$ Carroll, L. (1960). Alice's adventures in wonderland \& through the looking glass. New York, NY: Signet Classic.

5. Cole, R. (1999, January 18). Redefining diversity. Retrieved from PBS website: http://www.pbs.org/newshour/bb/education/jan-june99/diversity_1-18.html 
6. Howard, P. K. (1994). The death of common sense. City, ST: Warner Books.

7. McElroy, W. (2003, July 9). The PCSpeak of diversity. Retrieved from http://www.jewishworldreview.com/0703/mcelroy070903.asp

8. Sowell, T. (2003, February 15). Big business and quotas. Retrieved from http://www.jewishworldreview.com/cols/sowell021203.asp 


\section{NOTES}

